\title{
Efficacy and safety of aclidinium bromide/ formoterol fumarate fixed-dose combinations compared with individual components and placebo in patients with COPD (ACLIFORM-COPD): a multicentre, randomised study
}

Dave Singh $^{1 *}$, Paul W Jones ${ }^{2}$, Eric D Bateman ${ }^{3}$, Stephanie Korn ${ }^{4}$, Cristina Serra ${ }^{5}$, Eduard Molins ${ }^{6}$, Cynthia Caracta ${ }^{7}$, Esther Garcia Gil ${ }^{6}$ and Anne Leselbaum ${ }^{8}$

\begin{abstract}
Background: Aclidinium/formoterol is a twice-daily (BID) fixed-dose combination (FDC) in development for chronic obstructive pulmonary disease (COPD). The efficacy and safety of aclidinium/formoterol versus monotherapy and placebo in patients with COPD was assessed.

Methods: In this 24-week double-blind, parallel-group, active- and placebo-controlled, multicentre Phase III study, patients ( $\geq 40$ years, post-bronchodilator forced expiratory volume in 1 second [FEV $]$ /forced vital capacity $<70 \%$ and $\mathrm{FEV}_{1} \geq 30 \%$ but $<80 \%$ predicted normal) were randomised 2:2:2:2:1 to aclidinium/formoterol 400/12 $\mu \mathrm{g}$ $(n=385)$ or $400 / 6 \mu g(n=381)$, aclidinium $400 \mu \mathrm{g}(n=385)$, formoterol $12 \mu \mathrm{g}(n=384)$ or placebo $(n=194)$ BID via Genuair/Pressair ${ }^{\circ}$.
\end{abstract}

Results: At Week 24, aclidinium/formoterol 400/12 $\mu \mathrm{g}$ and 400/6 $\mu \mathrm{g}$ lead to significant improvements from baseline in 1-hour post-dose $\mathrm{FEV}_{1}$ versus aclidinium (125 mL [95\% Cl: 90, 160; $\left.\mathrm{p}<0.001\right]$ and $69 \mathrm{~mL}$ [95\% Cl: 34, $105 ; \mathrm{p}<0.001$, respectively) and trough $\mathrm{FEV}_{1}$ versus formoterol $(85 \mathrm{~mL}[95 \% \mathrm{Cl}: 51,119 ; \mathrm{p}<0.001]$ and $53 \mathrm{~mL}$ [95\% Cl: 19, 87; $\mathrm{p}<0.01$ ], respectively; co-primary endpoints). Additionally, aclidinium/formoterol 400/12 $\mu \mathrm{g}$ and 400/6 $\mu \mathrm{g}$ provided significant improvements in Transition Dyspnoea Index (TDI) focal score versus placebo (1.29 units [95\% Cl: 0.73, 1.86; $p<0.001]$ and 1.16 units [95\% Cl: 0.59, 1.73; $p<0.001]$, respectively; secondary endpoint). All treatments were well tolerated, with safety profiles of the FDCs similar to those of placebo and monotherapy.

Conclusions: Both aclidinium/formoterol BID doses significantly improved bronchodilation versus monotherapy, and dyspnoea versus placebo, with no increase in safety risk. Aclidinium/formoterol may be an effective treatment for patients with COPD.

Trial registration: ClinicalTrials.gov: NCT01462942.

Keywords: Aclidinium bromide/formoterol fumarate, Chronic obstructive pulmonary disease, Fixed-dose combination

\footnotetext{
* Correspondence: dsingh@meu.org.uk

'University of Manchester, Medicines Evaluation Unit, Langley Building, University Hospital of South Manchester NHS Foundation Trust, Southmoor Road, Manchester M23 9QZ, UK

Full list of author information is available at the end of the article
} 


\section{Background}

Inhaled long-acting bronchodilators (long-acting $\beta_{2}$-agonists [LABAs] and long-acting muscarinic antagonists [LAMAs]) are recommended as the first choice of treatment for patients with symptomatic chronic obstructive lung disease (COPD) [1]. LAMAs and LABAs relax airway smooth muscle by different mechanisms of action, and when combined may cause greater bronchodilation than a single agent [2,3]. A combined LABA/LAMA is a recommended treatment option in patients with moderate-to-severe COPD [1]. Although a LAMA and LABA can be administered together using separate inhalers (i.e. as a 'free combination'), this usage is not common, probably due to the inconvenience of handling separate devices [4]; delivery of medication with a single device is always more convenient for the patient. This has prompted the development of fixed-dose combinations (FDCs) of LAMAs and LABAs, such as glycopyrronium/indacaterol and umeclidinium/vilanterol, with the additional potential benefit of improved adherence to therapy [5].

Unlike many other LAMA/LABA FDCs, the combination of the LAMA aclidinium bromide and the LABA formoterol fumarate is administered twice daily (BID) [5-7]. BID dosing may provide a 24-hour profile of lung function improvements that has the potential to improve the night-time, early morning and day-time symptoms of COPD that are common in patients with this condition $[7,8]$.

This Phase III, randomised study aimed to compare bronchodilator efficacy, effects on symptoms and health status, and safety of two doses of aclidinium/formoterol FDC $(400 / 12 \mu \mathrm{g}$ and $400 / 6 \mu \mathrm{g})$ BID versus the monotherapy components (aclidinium $400 \mu \mathrm{g}$ and formoterol $12 \mu \mathrm{g}$ ) and placebo over six months in patients with stable, moderate-to-severe COPD.

\section{Methods}

Study design

The ACLIFORM-COPD study (ClinicalTrials.gov NCT 01462942) was a double-blind, randomised, parallelgroup, active- and placebo-controlled, multicentre study conducted at 193 centres in 22 countries (see Additional file 1). The first patient enrolled on 26 October 2011; the last patient completed 4 January 2013.

Following screening and a 2-3-week run-in period, patients with stable, moderate-to-severe COPD were randomised 2:2:2:2:1 to 24 weeks of double-blind treatment with twice-daily aclidinium/formoterol FDC $400 / 12 \mu \mathrm{g}$ or $400 / 6 \mu \mathrm{g}$, aclidinium $400 \mu \mathrm{g}$, formoterol $12 \mu \mathrm{g}$ or placebo, all via a breath-actuated, multiple-dose dry powder inhaler (Genuair /Pressair ${ }^{\circ}$; Almirall S.A., Barcelona, Spain).

This study was conducted in accordance with the Declaration of Helsinki, International Conference on
Harmonisation/Good Clinical Practice Guidelines, and local regulations. The protocol was approved by the regulatory authority for each country and an independent ethics committee at each centre (Additional file 1: Table S1). Patients gave written informed consent.

\section{Randomisation and masking}

Randomisation was performed using a centralised interactive voice response system on Day 1 (Visit 1), with stratification by smoking status (smoker or ex-smoker). Patients were instructed to administer one puff of study treatment at the same time in the morning (8:00-10:00 am) and evening (8:00-10:00 pm). Treatment identity was concealed with identical packaging/appearance and no odour or colour. Patients received training to use Genuair ${ }^{\circ}$ Pressair at screening and Visit 1.

\section{Study population and concomitant medication}

Male and female patients $\geq 40$ years of age who were current or former cigarette smokers with a smoking history $\geq 10$ pack-years and diagnosed with moderate-tosevere COPD according to GOLD 2010 criteria [9] (post-bronchodilator forced expiratory volume in 1 second $\left(\mathrm{FEV}_{1}\right) /$ forced vital capacity $(\mathrm{FVC})<70 \%$ and $\mathrm{FEV}_{1} \geq 30 \%$ but $<80 \%$ of predicted normal value) were eligible for inclusion (see Additional file 1 for exclusion criteria).

Inhaled salbutamol (100 $\mu \mathrm{g} / \mathrm{puff})$ was permitted as relief medication as needed, but discontinued 6 hours before planned study visits. Patients could continue inhaled corticosteroids (ICS) provided treatment was stable $\geq 4$ weeks pre-screening (see Additional file 1 for additional concomitant medications).

\section{Assessments}

Study assessments at each visit are outlined in Table 1. Spirometry $\left(\mathrm{FEV}_{1}\right)$ was performed pre-dose and up to 3 hours post-dose, with additional spirometry measurements performed in a subset of patients (12-hour spirometry sub-study; $\sim 20 \%$ of the intent-to-treat [ITT] population).

Dyspnoea was assessed at baseline using the Baseline Dyspnoea Index (BDI), with changes measured using the Transition Dyspnoea Index (TDI). Health status was assessed using St George's Respiratory Questionnaire (SGRQ). COPD symptoms (day-time, night-time and early morning) and relief medication use were recorded in an electronic diary. Day-time symptoms were assessed using the EXAcerbations of Chronic obstructive pulmonary disease Tool (EXACT), a 14-item diary completed every night [10,11]. Additionally, changes in specific respiratory symptoms (breathlessness, cough and sputum, and chest symptom domains) were assessed using the EXACT-Respiratory Symptoms score (E-RS; consisting of 
Table 1 Timeline of study assessments

\begin{tabular}{|c|c|c|c|c|c|c|c|c|}
\hline \multirow[b]{2}{*}{ Assessment } & \multirow{2}{*}{$\begin{array}{c}\text { Run-in } \\
\text { Week -3 to }-2 \\
\text { (Screening) }\end{array}$} & \multicolumn{6}{|c|}{ Double-blind treatment } & \multirow{2}{*}{$\begin{array}{c}\text { Follow-up } \\
\text { Week } 26 \\
\text { (Visit 7) }\end{array}$} \\
\hline & & $\begin{array}{c}\text { Day } 1 \\
(\text { Visit 1) }\end{array}$ & $\begin{array}{l}\text { Week } 1 \\
\text { (Visit 2) }\end{array}$ & $\begin{array}{l}\text { Week } 4 \\
\text { (Visit 3) }\end{array}$ & $\begin{array}{c}\text { Week } 12 \\
\text { (Visit 4) }\end{array}$ & $\begin{array}{c}\text { Week } 18 \\
\text { (Visit 5) }\end{array}$ & $\begin{array}{c}\text { Week } 24 \\
\text { (Visit 6) }\end{array}$ & \\
\hline Pre-dose spirometry ${ }^{b}$ & & $x$ & $x$ & $x$ & $x$ & $x$ & $x$ & \\
\hline Post-dose spirometry ${ }^{c}$ & & $x^{d}$ & $x$ & $x$ & $x$ & & $x$ & \\
\hline $\mathrm{BDI} / \mathrm{TD} \mathrm{e}^{\mathrm{e}}$ and SGRQ & & $X$ & & $x$ & $x$ & & $X$ & \\
\hline EXACT $^{f}$ & $x$ & $X$ & $x$ & $x$ & $x$ & $x$ & $X$ & \\
\hline NT and EM symptoms ${ }^{9}$ & $x$ & $x$ & $x$ & $x$ & $x$ & $x$ & $x$ & \\
\hline COPD exacerbations & & $X$ & $x$ & $X$ & $x$ & $x$ & $x$ & $x$ \\
\hline 12-hour spirometry sub-study ${ }^{\text {h }}$ & & $x$ & & & $x$ & & $x$ & \\
\hline AEs & $x$ & $x$ & $x$ & $x$ & $x$ & $x$ & $x$ & $x$ \\
\hline Laboratory tests (fasted) & $x$ & & & & $x^{i}$ & & $x^{i}$ & \\
\hline ECG and blood pressure & $x$ & $x^{j}$ & $x^{j}$ & $x^{j}$ & $x^{j}$ & & $x^{j}$ & \\
\hline 24-hour Holter sub-study & $x$ & & & & $x^{k}$ & & $x^{k}$ & \\
\hline
\end{tabular}

${ }^{\mathrm{a}}$ Randomisation visit; ${ }^{\mathrm{b}}$ Two sets of manoeuvres were performed during the hour pre-morning-dose; ${ }^{\mathrm{C}}$ One set of manoeuvres was performed at 0.5 , 1,2 , and 3 hours post-morning-dose; ${ }^{\mathrm{d}} \mathrm{An}$ additional set of manoeuvres was performed at 5 minutes post-morning-dose; ${ }^{\mathrm{B}} \mathrm{BDI}$ was used at Day 1 , TDI at all other visits; ${ }^{\mathrm{f}} \mathrm{EXACT}$ was completed every evening; ${ }^{9} \mathrm{NT}$ and EM symptoms were recorded every morning; ${ }^{\mathrm{h}}$ Additional spirometry measurements at $4,6,8,10$, and 12 hours post-morningdose were performed in a sub-set of patients; 'Blood samples were taken pre-morning-dose; ' $\mathrm{ECG}$ and blood pressure were measured pre- and 2-hours postmorning-dose; ${ }^{k} 24$-hour Holter recordings were started from 5 minutes pre-dose on the morning prior to these visits.

$A E$, adverse event; $B D I$, Baseline Dyspnoea Index; COPD, chronic obstructive pulmonary disease; ECG, electrocardiogram; EM, early morning; EXACT, EXAcerbations of Chronic obstructive pulmonary disease Tool; NT, night-time; SGRQ, St George's Respiratory Questionnaire; TDI, Transition Dyspnoea Index.

11 items of the 14-item EXACT) [12,13]. Night-time and early morning symptoms were assessed using a 14-item questionnaire completed every morning. COPD exacerbations were additionally assessed by Healthcare Resource Utilisation (HCRU) (see Additional file 1 for further details of symptoms assessments).

Safety assessments included recording of adverse events (AEs), laboratory tests, blood pressure measurements, 12-lead electrocardiograms (ECGs) and 24-hour 12-lead Holter recordings (sub-study, 20\% of the safety population). Major adverse cardiovascular events (MACE; a composite of total cardiovascular death, non-fatal myocardial infarction and non-fatal stroke) were evaluated and classified by an independent, blinded adjudication committee.

\section{Endpoints}

The co-primary endpoints were change from baseline at Week 24 in 1-hour morning post-dose $\mathrm{FEV}_{1}$ versus aclidinium $400 \mu \mathrm{g}$ and morning pre-dose (trough) $\mathrm{FEV}_{1}$ versus formoterol $12 \mu \mathrm{g}$; these endpoints were specified based on European Medicines Agency guidelines and US Federal Drug Administration regulations, which state that each drug in a fixed-dose combination must make a documented contribution within the combination to the claimed effects $[14,15]$. Secondary endpoints were TDI focal score and change from baseline in SGRQ total score at Week 24 (both versus placebo). Additional efficacy endpoints were change from baseline in $\mathrm{FEV}_{1}$ during 3 hours post-dose, peak $\mathrm{FEV}_{1}$, TDI and SGRQ responders (\% patients achieving the minimum clinically important difference [MCID] in TDI [ $\geq 1$ unit increase] and SGRQ [ $\geq 4$ units]); changes from baseline in COPD symptoms (total EXACT-Respiratory Symptoms [E-RS] score, and night-time and early morning symptoms scores); rate of COPD exacerbations (HCRU and EXACT); and change from baseline in relief medication use.

\section{Statistical analysis}

Data were analysed using SAS $^{\circ}$ Version 9.3. Efficacy analyses, with the exception of exacerbation rate, were performed on the ITT population (patients who took $\geq 1$ dose of study medication and had a baseline and $\geq 1$ post-baseline $\mathrm{FEV}_{1}$ assessment). Exacerbations and safety outcomes were assessed in the safety population (patients who received $\geq 1$ dose of study medication).

A sample size of 1575 (350 per active treatment; 175 placebo) was estimated to provide $\geq 90 \%$ power to detect a significant difference of $100 \mathrm{~mL}$ between aclidinium/ formoterol FDC and aclidinium in change from baseline in 1-hour post-dose $\mathrm{FEV}_{1}$ (with standard deviation [SD] $280 \mathrm{~mL}$ ); $65 \mathrm{~mL}$ between aclidinium/formoterol FDC and formoterol $12 \mu \mathrm{g}$ in change from baseline in trough $\mathrm{FEV}_{1}$ (with SD $260 \mathrm{~mL}$ ); and $\geq 1$ unit difference in TDI focal score (with SD 3.4 units) and $\geq 4$ unit difference in SGRQ total score (with SD 12.8 units) between aclidinium/formoterol FDC and placebo at Week 24 using two-sided tests and adjusting for multiple tests at the overall significance level of 0.05 .

Pulmonary function variables, COPD symptoms (including TDI focal score), SGRQ total score and relief medication use were analysed by means of a mixed model 
for repeated measures (MMRM), adjusted by age and baseline value as covariates, and treatment group, sex, smoking status, visit and treatment group-by-visit interaction as fixed-effect factors. The MMRM for FEV variables was additionally adjusted by screening pre- and post-bronchodilator (salbutamol) $\mathrm{FEV}_{1}$ as a covariate. Efficacy variable treatment effects and treatment differences were estimated by least squares (LS) means. Safety outcomes were analysed descriptively for the safety population. Additionally, regression analyses were performed for exacerbation rate (see Additional file 1).

\section{Results}

Of 2443 patients screened, 1729 were included in the safety analysis set; three patients were excluded from the ITT population due to missing $\mathrm{FEV}_{1}$ data (Figure 1). In total, 203 (11.7\%) patients discontinued treatment; more patients in the placebo group withdrew prematurely (17.5\%) compared with active treatments (8.8-13.0\%). The primary reasons for withdrawal were patient request (4.2\%), AEs other than COPD exacerbation $(2.9 \%)$ and protocol non-compliance (2.0\%).

Demographics and baseline characteristics were similar across treatment groups (Table 2). Post-bronchodilator $\mathrm{FEV}_{1}$ was approximately $55 \%$ in all treatment groups. Prior to the study, $19.8 \%$ of patients were using ICS as monotherapy (or in free combination) and $31.8 \%$ of patients were using ICS in fixed-dose combination with a LABA (Table 2).

\section{Pulmonary function}

At Week 24, aclidinium/formoterol FDC 400/12 $\mu \mathrm{g}$ and 400/6 $\mu \mathrm{g}$ caused significantly greater changes from baseline in 1-hour morning post-dose $\mathrm{FEV}_{1}$ compared with placebo (LS means: $299 \mathrm{~mL}$ and $244 \mathrm{~mL}$, respectively; both $\mathrm{p}<0.001$; Figure 2a). Aclidinium and formoterol monotherapies also caused improvements compared with placebo (LS means: $174 \mathrm{~mL}$ and $160 \mathrm{~mL}$, respectively; both $\mathrm{p}<0.001$; Figure $2 \mathrm{a}$ ). Figure $2 \mathrm{~b}$ shows that these $\mathrm{FEV}_{1}$ changes were significantly greater with both FDC $400 / 12 \mu \mathrm{g}$ and $400 / 6 \mu \mathrm{g}$ versus either monotherapy at all timepoints (LS means at Week 24: $125 \mathrm{~mL}$ and $69 \mathrm{~mL}$, respectively, versus aclidinium [both $\mathrm{p}<0.001$ ]; $139 \mathrm{~mL}$ and $84 \mathrm{~mL}$ versus formoterol [both $\mathrm{p}<0.001$ ]); the $400 / 12 \mu \mathrm{g}$ dose was statistically superior to the 400/6 $\mu \mathrm{g}$ dose at all visits except Week 12 (all $\mathrm{p}<0.05$ ).

Aclidinium/formoterol FDC 400/12 $\mu \mathrm{g}$ and 400/6 $\mu \mathrm{g}$ caused significantly greater changes from baseline in trough $\mathrm{FEV}_{1}$ at Week 24 compared with placebo (LS means: $143 \mathrm{~mL}$ and $111 \mathrm{~mL}$, respectively; both $\mathrm{p}<0.001$; Figure 3a). Aclidinium and formoterol monotherapies also caused improvements compared with placebo (LS means: $117 \mathrm{~mL}[\mathrm{p}<0.001]$ and $58 \mathrm{~mL}[\mathrm{p}<0.01]$, respectively; Figure 3a). Figure $3 \mathrm{~b}$ shows that these $\mathrm{FEV}_{1}$ changes were significantly greater with FDC 400/12 $\mu \mathrm{g}$ and $400 / 6 \mu \mathrm{g}$ versus formoterol at all timepoints (LS means at Week 24: $85 \mathrm{~mL}[\mathrm{p}<0.001]$ and $53 \mathrm{~mL}[\mathrm{p}<0.01]$, respectively). Compared with aclidinium, improvements were numerically greater with FDC 400/12 $\mu \mathrm{g}$ at all visits and significantly greater at Weeks 1 and 4 .

The onset of action of both FDC doses on Day 1 was fast, with significant improvements in bronchodilation versus placebo at 5 minutes post-dose (Additional file 1: Figure S1). The change in $\mathrm{FEV}_{1}$ over 3 hours postdose, peak $\mathrm{FEV}_{1}$ and results of 12-hour spirometry are presented in Additional file 1. Generally, significant

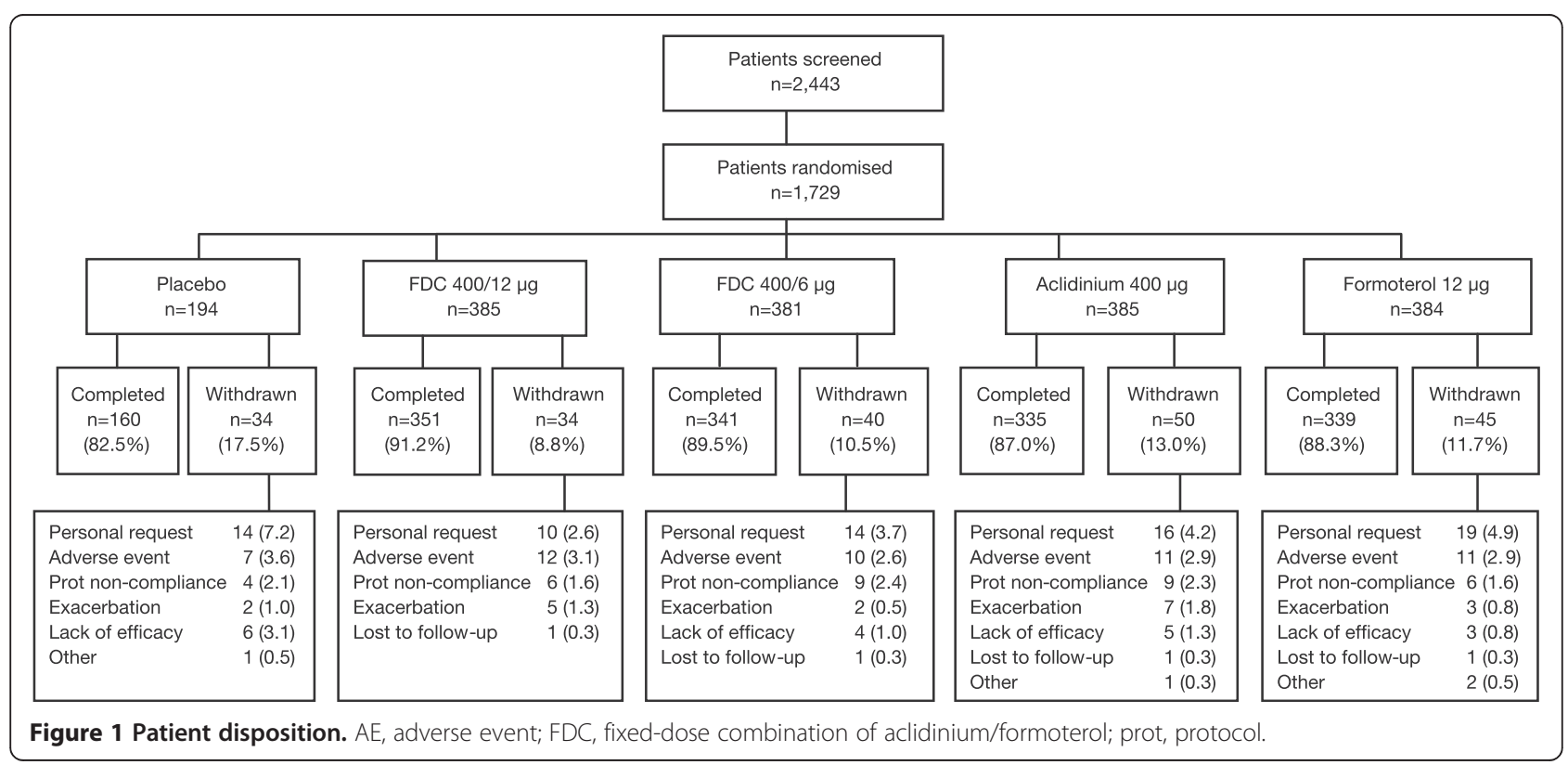


Table 2 Patient demographics and baseline characteristics (safety population)

\begin{tabular}{|c|c|c|c|c|c|c|}
\hline & Placebo & $\begin{array}{c}\text { FDC } \\
400 / 12 \mu \mathrm{g}\end{array}$ & $\begin{array}{c}\text { FDC } \\
400 / 6 \mu \mathrm{g}\end{array}$ & $\begin{array}{c}\text { Aclidinium } \\
400 \mu \mathrm{g}\end{array}$ & $\begin{array}{l}\text { Formoterol } \\
12 \mu \mathrm{g}\end{array}$ & Total \\
\hline Patients, n & 194 & 385 & 381 & 385 & 384 & 1729 \\
\hline Age, years & $64.2 \pm 8.0$ & $62.7 \pm 8.1$ & $62.9 \pm 7.7$ & $63.1 \pm 8.2$ & $63.4 \pm 7.8$ & $63.2 \pm 8.0$ \\
\hline Males, n (\%) & $138(71.1)$ & $261(67.8)$ & $259(68.0)$ & $256(66.5)$ & $255(66.4)$ & 1169 (67.6) \\
\hline Caucasians, n (\%) & $183(94.3)$ & $367(95.3)$ & $366(96.1)$ & $363(94.3)$ & $362(94.3)$ & $1641(94.9)$ \\
\hline Current smoker, n (\%) & $94(48.5)$ & $181(47.0)$ & $182(47.8)$ & $182(47.3)$ & $179(46.6)$ & $818(47.3)$ \\
\hline \multicolumn{7}{|c|}{ Severity of airflow obstruction, n (\%), based on GOLD 2010 criteria $^{a}$} \\
\hline Moderate & $116(60.1)$ & $229(59.5)$ & $230(60.4)$ & $226(58.9)$ & $237(61.9)$ & $1038(60.1)$ \\
\hline Severe & $77(39.9)$ & $156(40.5)$ & $151(39.6)$ & $157(40.9)$ & $144(37.6)$ & $685(39.7)$ \\
\hline Baseline FEV $1, \mathrm{~L}$ & $1.42 \pm 0.54$ & $1.42 \pm 0.49$ & $1.41 \pm 0.48$ & $1.40 \pm 0.51$ & $1.40 \pm 0.48$ & $1.41 \pm 0.50$ \\
\hline Post-bronchodilator $\mathrm{FEV}_{1}, \%$ predicted & $55.0 \pm 13.4$ & $54.6 \pm 13.1$ & $54.1 \pm 13.0$ & $53.6 \pm 13.0$ & $54.5 \pm 13.2$ & $54.3 \pm 13.1$ \\
\hline Patients meeting bronchial reversibility criteria, $\mathrm{n}(\%)^{\mathrm{b}}$ & $66(34.0)$ & $134(34.8)$ & $127(33.3)$ & $125(32.6)$ & $114(29.8)$ & $566(32.8)$ \\
\hline \multicolumn{7}{|l|}{ Prior COPD medication, n (\%) } \\
\hline Any COPD-related medication & $167(86.1)$ & $330(85.7)$ & $331(86.9)$ & $337(87.5)$ & $329(85.7)$ & $1494(86.4)$ \\
\hline$L A B A+I C S^{C}$ & $63(32.5)$ & $118(30.6)$ & $128(33.6)$ & $121(31.4)$ & $119(31.0)$ & $549(31.8)$ \\
\hline LAMA & $60(30.9)$ & $118(30.6)$ & $122(32.0)$ & $107(27.8)$ & $110(28.6)$ & $517(29.9)$ \\
\hline LABA & 38 (19.6) & 79 (20.5) & $69(18.1)$ & $78(20.3)$ & $80(20.8)$ & $344(19.9)$ \\
\hline ICS & $39(20.1)$ & $85(22.1)$ & $72(18.9)$ & 79 (20.5) & $68(17.7)$ & $343(19.8)$ \\
\hline BDI focal score & $6.6 \pm 2.0$ & $6.6 \pm 2.1$ & $6.6 \pm 2.0$ & $6.5 \pm 2.0$ & $6.5 \pm 2.1$ & $6.5 \pm 2.1$ \\
\hline SGRQ total score & $45.8 \pm 17.6$ & $46.1 \pm 17.9$ & $46.7 \pm 17.6$ & $46.8 \pm 16.8$ & $45.2 \pm 18.2$ & $46.2 \pm 17.6$ \\
\hline
\end{tabular}

${ }^{a}$ One patient randomised to formoterol $12 \mu \mathrm{g}$ had mild COPD at baseline; one patient each randomised to formoterol $12 \mu \mathrm{g}$ and aclidinium $400 \mu \mathrm{g}$ had very severe COPD at baseline; ${ }^{b}$ Bronchial reversibility $\geq 12 \%$ and change in FEV ${ }_{1}$ from pre-test $\geq 200 \mathrm{~mL}$; ${ }^{\mathrm{C}} \mathrm{LABA}$ and ICS in fixed-dose combination.

Data are presented as mean $\pm S D$, unless otherwise stated.

$\mathrm{BDI}$, Baseline Dyspnoea Index; COPD, chronic obstructive pulmonary disease; FDC, aclidinium/formoterol fixed-dose combination; FEV 1 , forced expiratory volume in 1 second; GOLD, Global Initiative for Chronic Obstructive Lung Disease; ICS, inhaled corticosteroid; LABA, long-acting $\beta_{2}$-adrenergic agonist; LAMA, long-acting muscarinic antagonist; SD, standard deviation; SGRQ, St George's Respiratory Questionnaire.

improvements in these parameters were observed with FDC at all visits compared with placebo and one or both monotherapies.

\section{Symptoms}

At Week 24, both FDC doses caused clinically significant improvements ( $\geq 1$ unit) in TDI focal score versus placebo (400/12 $\mu \mathrm{g}: 1.29$ units and 400/6 $\mu \mathrm{g}$ : 1.16 units; both $\mathrm{p}<0.001$; Figure 4). Aclidinium and formoterol monotherapies caused significant improvements (both $\mathrm{p}<0.005$ ) versus placebo at Week 24 that fell just below the 1-unit threshold. The differences between both FDC doses versus the monotherapies were not statistically significant (Additional file 1: Table S2). A significantly higher proportion of FDC-treated and monotherapy-treated patients had $\geq 1$ unit improvement in TDI focal score at Week 24 versus placebo (Additional file 1: Table S2).

The improvements in overall E-RS symptoms with both FDC doses were significantly greater compared with the monotherapies and placebo (all comparisons $\mathrm{p}<0.05$ ); changes from baseline in night-time and early morning symptoms scores followed a similar pattern, although not all comparisons reached statistical significance (see Additional file 1).

COPD exacerbations data are presented in Additional file 1. The rate of HCRU exacerbations was low across treatment arms (0.26-0.41 per patient per year) and although the rate was numerically lower with both FDC doses compared with placebo, this difference was not statistically significant. When assessed with EXACT, higher exacerbation rates were observed (1.09-1.54 per patient per year) and the FDC 400/12 $\mu \mathrm{g}$ dose significantly reduced the rate of exacerbations compared with placebo (see Additional file 1: Table S3). During the 24 treatment weeks, the number of patients hospitalised due to exacerbations (based on HCRU data) was low and similar between treatment groups (placebo: $\mathrm{n}=5$ [2.6\%]; FDC 400/12 $\mu \mathrm{g}: \mathrm{n}=4$ [1.0\%]; FDC 400/6 $\mu \mathrm{g}$ : $\mathrm{n}=3$ [0.8\%]; aclidinium $400 \mu \mathrm{g}: \mathrm{n}=7$ [1.8\%]; formoterol $12 \mu \mathrm{g}: \mathrm{n}=1[0.3 \%])$.

\section{Health-related quality of life}

At Week 24, all active treatments were associated with improvements in mean SGRQ total score $>4$ units (Figure 5); however, there was a very high placebo response and 

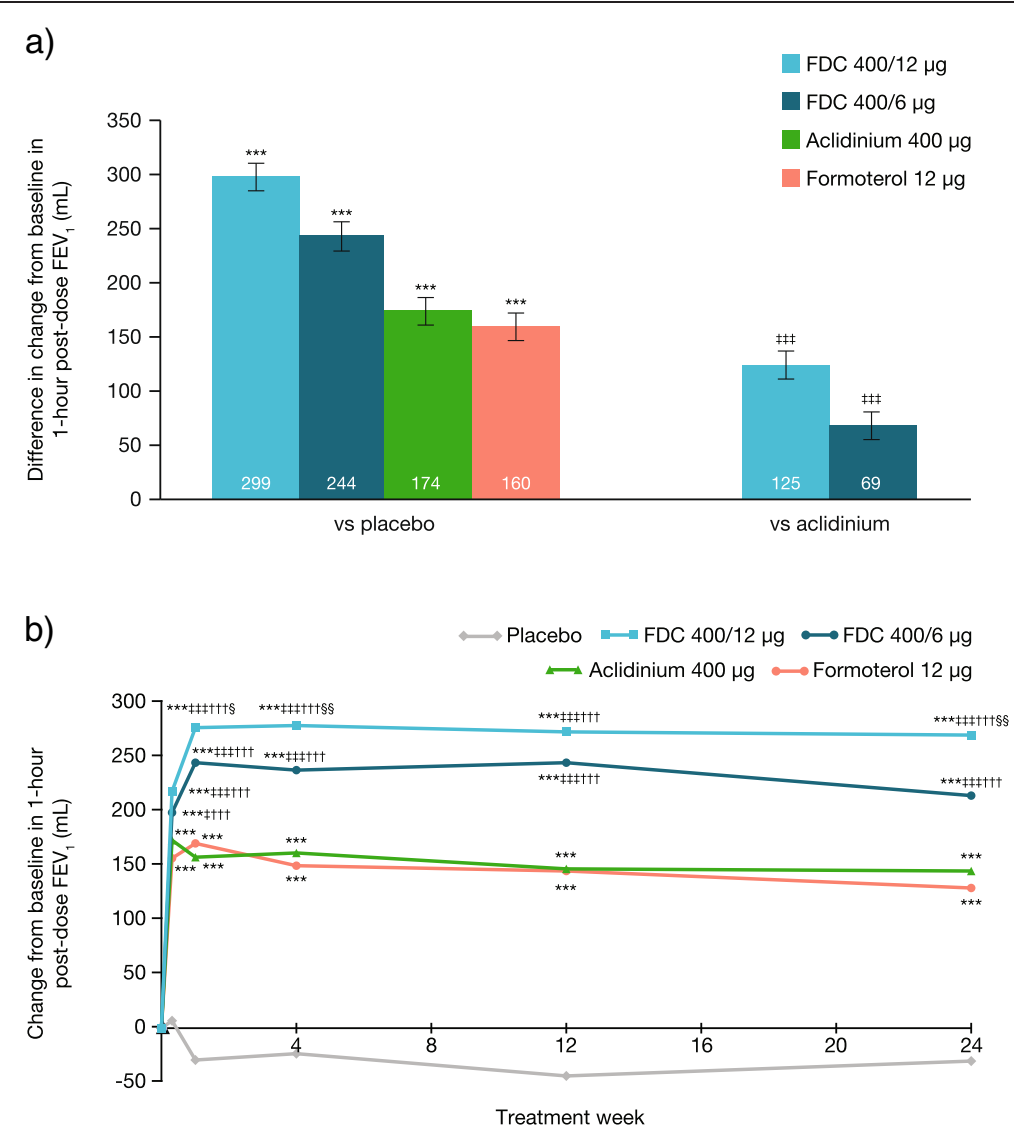

Figure 2 Mean treatment differences for change from baseline in 1-hour post-dose FEV . (a) At Week 24; (b) Over 24 weeks; Data are presented as least squares means (SE) for the ITT population. ${ }^{* * *} p<0.001$ vs placebo; ${ }^{\ddagger} p<0.05 ;{ }^{\ddagger \neq \neq} p<0.001$ vs aclidinium; ${ }^{+1 \dagger} p<0.001$ vs formoterol; ${ }^{\S} \mathrm{p}<0.05 ;{ }^{\S \S} \mathrm{p}<0.01$ vs FDC $400 / 6 \mu \mathrm{g}$. FDC, aclidinium/formoterol fixed-dose combination; FEV ${ }_{1}$, forced expiratory volume in 1 second; ITT, intent-to-treat; $S E$, standard error.

there were no statistically significant differences between active and placebo treatments (Additional file 1: Table S2). A significantly higher proportion of patients receiving FDC $400 / 6 \mu \mathrm{g}$ had $\geq 4$ units decrease in SGRQ total score at Week 24 versus placebo (see Additional file 1).

\section{Relief medication use}

Mean treatment differences in overall daily use of relief medication versus placebo were -0.66 with FDC $400 / 12 \mu \mathrm{g}(\mathrm{p}<0.001)$ and -0.73 with $400 / 6 \mu \mathrm{g}(\mathrm{p}<0.001)$. These changes from baseline with both FDC doses were significantly greater than aclidinium monotherapy (both $\mathrm{p}<0.05$ ), but not compared with formoterol monotherapy.

\section{Safety}

The incidence of treatment-emergent AEs (TEAEs) was similar across study arms (Table 3, also see Additional file 1). The proportion of patients experiencing a serious $\mathrm{AE}(\mathrm{SAE})$ was low (4.8\%) and comparable between treatment groups (Table 3). The most frequently reported SAE was COPD exacerbation (Table 3).

The incidence of MACE was low and comparable across all study arms (see Additional file 1). TEAEs associated with anticholinergic or $\beta_{2}$-adrenergic activity generally occurred in $<3 \%$ of patients in any treatment group. The exception was headache ( $\beta_{2}$-adrenergic TEAE), reported in $7.1 \%-11.2 \%$ of patients. There were four fatal TEAEs (see Additional file 1); none were considered related to study medication. There were no clinically significant differences between treatment groups in clinical laboratory tests, vital signs and ECGs (including 24-hour Holter ECG monitoring; Additional file 1: Table S4).

There were four fatal TEAEs: one in the aclidinium/ formoterol 400/12 $\mu$ g group (COPD exacerbation), two in the aclidinium/formoterol 400/6 $\mu \mathrm{g}$ group (COPD exacerbation $[n=1]$ and cardiac failure $[n=1])$ and one in the formoterol $12 \mu \mathrm{g}$ group (cardiac failure). None of these were considered to be related to study medication and all four patients had multiple underlying comorbidities including prior cardiac failure, coronary artery disease and hypertension. 

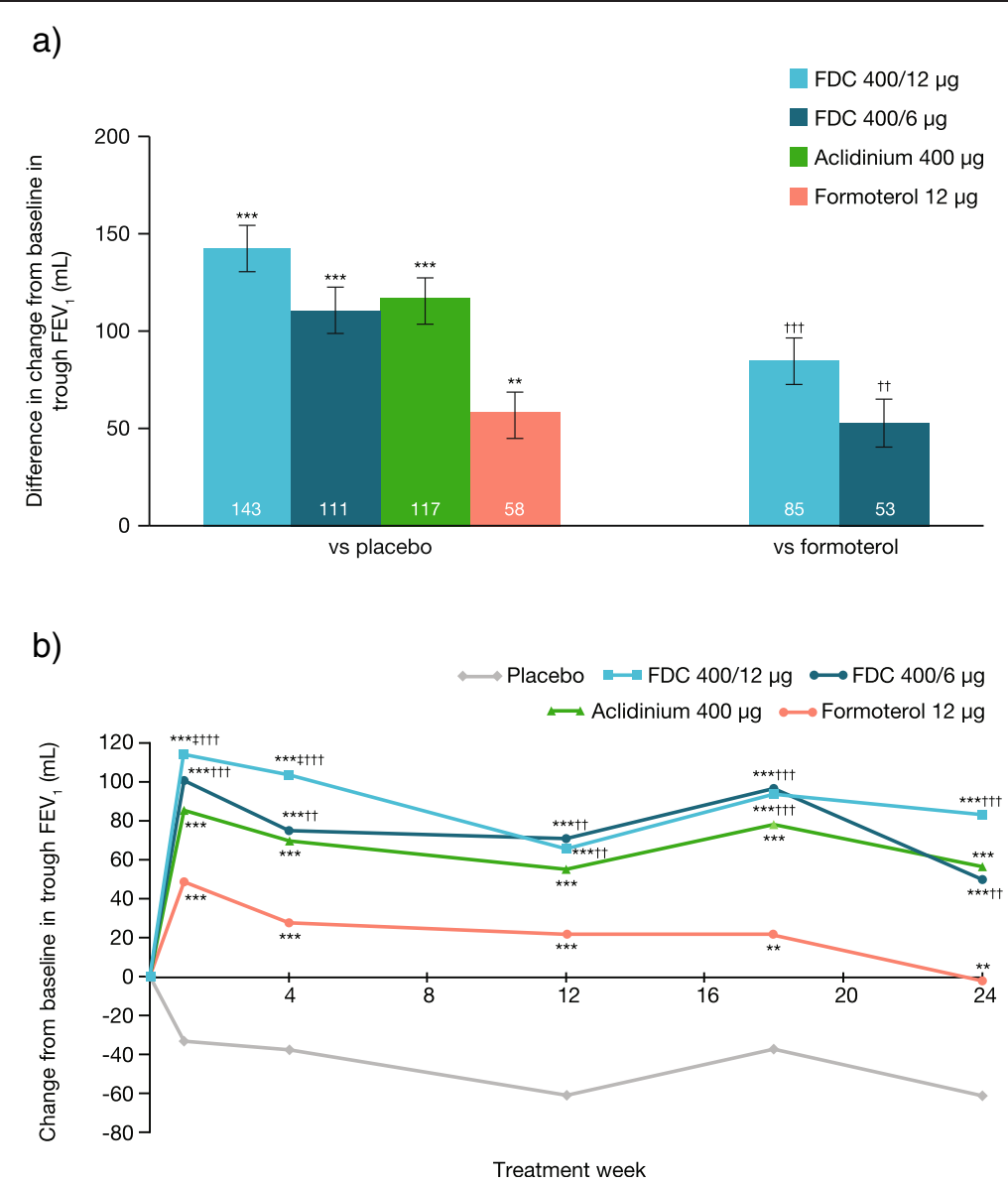

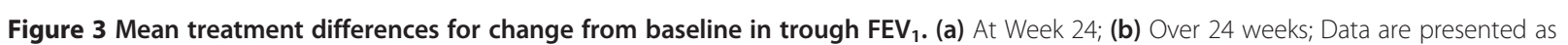
least squares means (SE) for the ITT population. ${ }^{* *} p<0.01$; ${ }^{* *} p<0.001$ vs placebo; ${ }^{*} p<0.05$ vs aclidinium; ${ }^{\dagger+} p<0.01 ;{ }^{+\dagger+} p<0.001$ vs formoterol. FDC, aclidinium/formoterol fixed-dose combination of aclidinium/formoterol; FEV ${ }_{1}$, forced expiratory volume in 1 second; ITT, intent-to-treat; SE, standard error.

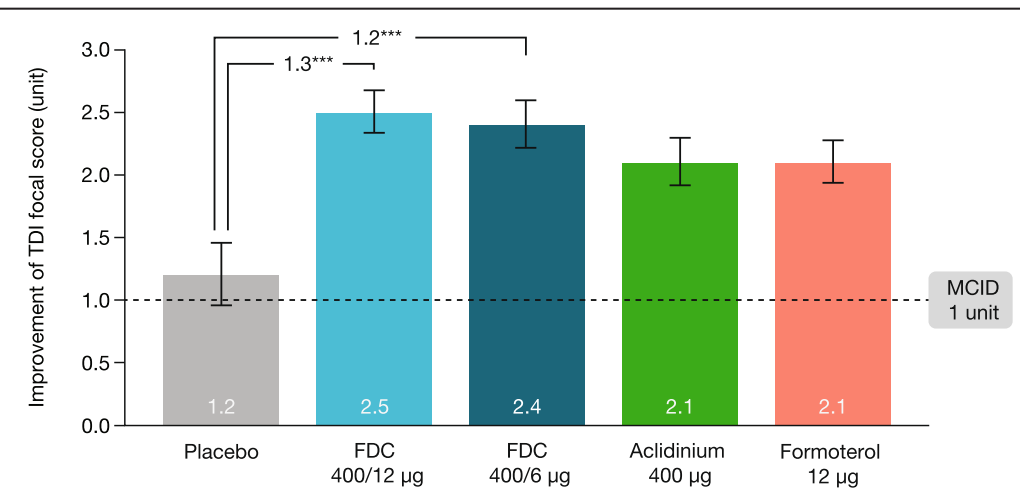

Figure 4 Improvement in TDI focal score at 24 weeks (ITT population). Data are presented as least squares means (SE). ${ }^{* * *} \mathrm{p}<0.001$ VS placebo. FDC, aclidinium/formoterol fixed-dose combination; ITT, intent-to-treat; MCID, minimum clinically important difference; SE, standard error; TDI, transition dyspnoea index. 


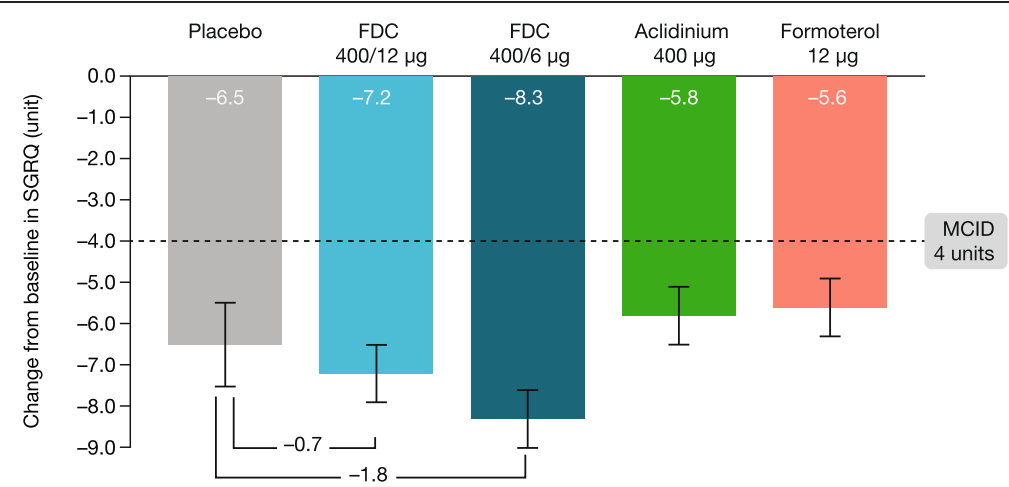

Figure 5 Change from baseline in SGRQ total score at $\mathbf{2 4}$ weeks (ITT population). Data are presented as least squares means (SE). FDC, aclidinium/formoterol fixed-dose combination; ITT, intent-to-treat; MCID, minimum clinically important difference; SE, standard error; SGRQ, St George's Respiratory Questionnaire.

\section{Discussion}

Both doses of aclidinium/formoterol FDC BID significantly improved pulmonary function after 24 weeks compared to the monotherapy components and placebo in patients with moderate-to-severe COPD. The greatest improvements were seen with the higher aclidinium/ formoterol FDC dose. Clinical benefits with aclidinium/ formoterol FDC were achieved without an increased risk of AEs.

The pre-defined co-primary endpoints in this study were chosen to test the individual contributions of the component therapies, i.e. rapid-onset bronchodilation with formoterol (change from baseline in $\mathrm{FEV}_{1}$ at 1-hour post-morning dose) [5,16,17], and 24-hour

Table 3 Number (\%) of patients with TEAEs, TESAEs and discontinuations (safety population)

\begin{tabular}{|c|c|c|c|c|c|}
\hline n (\%) & $\begin{array}{l}\text { Placebo } \\
(n=194)\end{array}$ & $\begin{array}{c}\text { FDC } \\
400 / 12 \mu \mathrm{g} \\
(n=385)\end{array}$ & $\begin{array}{c}\text { FDC } \\
400 / 6 \mu \mathrm{g} \\
(n=381)\end{array}$ & $\begin{array}{c}\text { Aclidinium } \\
400 \mu \mathrm{g} \\
(\mathrm{n}=385)\end{array}$ & $\begin{array}{c}\text { Formoterol } \\
12 \mu \mathrm{g} \\
(\mathrm{n}=384) \\
\end{array}$ \\
\hline Any TEAE & $103(53.1)$ & $194(50.4)$ & $193(50.7)$ & $190(49.4)$ & $217(56.5)$ \\
\hline \multicolumn{6}{|c|}{ TEAEs in $\geq 2 \%$ of any treatment group (by preferred term) } \\
\hline COPD exacerbation & $27(13.9)$ & $36(9.4)$ & $38(10.0)$ & $46(11.9)$ & $60(15.6)$ \\
\hline Headache & $16(8.2)$ & $29(7.5)$ & $27(7.1)$ & $35(9.1)$ & $43(11.2)$ \\
\hline Nasopharyngitis & $14(7.2)$ & $30(7.8)$ & $30(7.9)$ & $22(5.7)$ & $26(6.8)$ \\
\hline Back pain & $9(4.6)$ & $18(4.7)$ & $13(3.4)$ & $20(5.2)$ & $19(4.9)$ \\
\hline Diarrhoea & $5(2.6)$ & $6(1.6)$ & $5(1.3)$ & $2(0.5)$ & $6(1.6)$ \\
\hline Nausea & $5(2.6)$ & $3(0.8)$ & $4(1.0)$ & $4(1.0)$ & $1(0.3)$ \\
\hline Abdominal pain, upper & $4(2.1)$ & $2(0.5)$ & $3(0.8)$ & $4(1.0)$ & $6(1.6)$ \\
\hline Arthralgia & $3(1.5)$ & $6(1.6)$ & $3(0.8)$ & $3(0.8)$ & $12(3.1)$ \\
\hline URTI & $3(1.5)$ & $8(2.1)$ & $4(1.0)$ & $7(1.8)$ & $10(2.6)$ \\
\hline Hypertension & $2(1.0)$ & $3(0.8)$ & $4(1.0)$ & $2(0.5)$ & $9(2.3)$ \\
\hline Sinusitis & $1(0.5)$ & $3(0.8)$ & $10(2.6)$ & $3(0.8)$ & $3(0.8)$ \\
\hline Rhinitis & $1(0.5)$ & $2(0.5)$ & $6(1.6)$ & $2(0.5)$ & $10(2.6)$ \\
\hline Oropharyngeal pain & $1(0.5)$ & $10(2.6)$ & $2(0.5)$ & $5(1.3)$ & $2(0.5)$ \\
\hline TEAEs leading to discontinuation & $8(4.1)$ & $16(4.2)$ & $12(3.1)$ & $17(4.4)$ & $14(3.6)$ \\
\hline TESAES & $12(6.2)$ & $23(6.0)$ & $18(4.7)$ & $16(4.2)$ & $14(3.6)$ \\
\hline \multicolumn{6}{|c|}{ TESAEs occurring in $>2$ patients in any treatment group (by preferred term) } \\
\hline COPD exacerbation & $5(2.6)$ & $4(1.0)$ & $4(1.0)$ & $7(1.8)$ & $1(0.3)$ \\
\hline Pneumonia & $1(0.5)$ & $3(0.8)$ & $4(1.0)$ & $0(0.0)$ & $0(0.0)$ \\
\hline
\end{tabular}


bronchodilation with twice-daily aclidinium (change from baseline in trough $\mathrm{FEV}_{1}$ ) $[18,19]$. Both doses of aclidinium/formoterol FDC met both co-primary endpoints, suggesting that aclidinium/formoterol FDC provides bronchodilation that is faster in onset than aclidinium and of a greater magnitude over the dosing interval than formoterol. To date, all LAMA/LABA FDCs have demonstrated superiority to their monocomponents for improvements in $\mathrm{FEV}_{1}$, and our study shows similar results [20-24]. Taken together, the results provide good evidence that LAMA/LABA FDCs deliver additional clinical benefits versus monotherapy. Currently, there is no established MCID in bronchodilation for combination therapies versus their monotherapy components [25]. In this study, the treatment differences versus monotherapy were generally greater with the 400/12 $\mu \mathrm{g}$ dose compared with the 400/6 $\mu \mathrm{g}$ dose for bronchodilation endpoints (change from baseline in 1-hour post-dose $\mathrm{FEV}_{1}$, trough and peak $\mathrm{FEV}_{1}, \mathrm{FEV}_{1}$ over 3 hours post-dose and normalised $\mathrm{FEV}_{1} \mathrm{AUC}_{0-12}$ ).

Both aclidinium/formoterol FDC doses improved trough $\mathrm{FEV}_{1}$ by $>100 \mathrm{~mL}$ compared with placebo; this threshold is a clinically meaningful change [26]. The contribution of aclidinium to the increase from baseline in trough $\mathrm{FEV}_{1}$ seen with aclidinium/formoterol 400/12 $\mu \mathrm{g}(85 \mathrm{~mL}$ versus formoterol) is within the range observed for the monocomponents of other LAMA/LABA combinations (70-95 mL versus LABA) [21,22]. However, caution should be applied when comparing effect sizes between studies and head-to-head studies are required for more meaningful comparisons.

Both aclidinium/formoterol FDC doses provided clinically meaningful ( $\geq 1$ unit) improvements in TDI focal score versus placebo with more patients achieving a $\geq 1$-unit improvement. The change in TDI in the placebo group makes comparisons of the change versus placebo difficult; however, the magnitude of change in the placebo group (1.2 units) is the same as that observed in other studies $[21,22]$ and the changes from baseline of 2.5 and 2.4 units for FDC 400/12 $\mu \mathrm{g}$ and 400/6 $\mu \mathrm{g}$, respectively, clearly exceed the MCID. The magnitude of improvement was numerically greater than that seen with both monotherapies, although the study was not powered to detect differences between aclidinium/formoterol FDC and monotherapy for TDI or SGRQ. Much of the data for MCID in TDI focal score and SGRQ total score has been reported from placebo-controlled trials, where the treatment effects can be large; for studies investigating the incremental gain from adding one active treatment on top of another, it is likely that the treatment effects will be smaller than the differences between monotherapies and placebo [25].

A 'Hawthorne effect' often occurs in COPD trials whereby patients treated with placebo improve by participating in a clinical study [27], particularly in countries where healthcare is not free or easily accessible. However, the SGRQ total score improvement observed in the placebo group (-6.5 units) was considerably larger than that observed in most other COPD clinical trials; a meta-analysis of long-acting bronchodilator COPD trials showed the placebo effect on SGRQ to be typically 2 units, with no studies demonstrating increases of $>5$ units [28]. The large and mostly unexplained placebo effect that we observed resulted in neither aclidinium/formoterol FDC dose, causing significantly greater SGRQ improvements compared with placebo, despite producing large changes from baseline. However, responder analysis based on the proportion with $\geq 4$-unit improvement did show a benefit with FDC $400 / 6 \mu$ g. Post-hoc analyses showed that $\sim 90 \%$ of patients were randomised during winter/spring and treatment continued into the spring/summer period when exacerbation rates are lower [29]; this probably contributed to the low exacerbation rate in the study and large improvement in health status in the placebo arm.

Patients with COPD often report a range of symptoms during normal sleeping hours and on waking [30], and early morning has been reported as the time of day when COPD symptoms are most troublesome [8]. Total daily symptom scores, assessed using the recently validated E-RS questionnaire $[12,13]$, were significantly lower with aclidinium/formoterol FDC versus placebo and both monotherapies. In addition, night-time and early morning symptoms were improved with aclidinium/ formoterol FDC versus placebo and aclidinium. Aclidinium twice-daily has been shown to improve night-time and early morning symptoms [18] and our results suggest that aclidinium/formoterol FDC 400/12 $\mu \mathrm{g}$ provides greater improvements across the whole 24 hours than aclidinium monotherapy.

Both aclidinium/formoterol FDC doses were well tolerated. There was no evidence for additive AEs when combining the two different drugs and no evidence of an increase in AEs at the higher FDC dose. These safety data are consistent with the fact that formoterol is a well-tolerated drug [31] and aclidinium has low systemic exposure, minimising the potential for typical LAMA side effects [32,33]. Furthermore, the 24-hour Holtermonitoring showed no evidence that aclidinium/formoterol FDC increased ECG abnormalities compared with placebo.

\section{Conclusions}

The twice-daily LAMA/LABA aclidinium/formoterol FDCs had a rapid and sustained effect on lung function, with significant improvements in bronchodilation compared with monotherapy and COPD symptoms compared with placebo. Overall, the benefits seen with aclidinium/ formoterol FDC $400 / 12 \mu \mathrm{g}$ were greater than those seen 
with the 400/6 $\mu \mathrm{g}$ dose. Both doses were well tolerated and had similar safety profiles to placebo. These results suggest that aclidinium/formoterol FDC may be an effective new treatment option as a dual bronchodilator for patients with moderate-to-severe COPD.

\section{Endnote}

${ }^{a}$ Registered trademarks of AstraZeneca PLC, Barcelona, Spain; for use as Pressair ${ }^{\circ}$ within the USA and Genuair ${ }^{\circ}$ within all other licensed territories.

\section{Additional file}

\section{Additional file 1: Online supplement.}

\section{Abbreviations}

AE: Adverse event; BDI: Baseline dyspnoea index; BID: Twice daily; COPD: Chronic obstructive pulmonary disease; ECG: Electrocardiogram; E-RS: EXACT-respiratory symptoms; EXACT: EXAcerbations of Chronic obstructive pulmonary disease Tool; FDC: Fixed-dose combination; $\mathrm{FEV}_{1}$ : Forced expiratory volume in 1 second; FVC: Forced vital capacity; HCRU: Healthcare resource utilisation; ICS: Inhaled corticosteroids: ITT: Intent-to-treat; LABA: Long-acting $\beta_{2}$-adrenergic agonist; LAMA: Long-acting muscarinic antagonist; LS: Least squares; MACE: Major adverse cardiovascular event; MCID: Minimal clinically important difference; MMRM: Mixed model for repeated measures; SAE: Serious adverse event; SD: Standard deviation; SGRQ: St George's respiratory questionnaire; TDI: Transition dyspnoea index; TEAE: Treatment emergent adverse event.

\section{Competing interests}

DS has received sponsorship to attend international meetings, honoraria for lecturing or attending advisory boards and research grants from various pharmaceutical companies including Almirall, AstraZeneca, Boehringer Ingelheim, Chiesi, CIPLA, Forest, Genentech, GlaxoSmithKline, Merck, Novartis, Pfizer, and Takeda.

PJ has received speaker and consulting fees from Almirall. His institution has also received payment for his participation in advisory boards, consultancy, lectures, or developing educational materials from AstraZeneca, GlaxoSmithKline, United BioSource, Chiesi, Janssen, Medimmune, Novartis, and Roche; his institution has received grants from GlaxoSmithKline. EB has received grants for studies for his institution and personal fees from Actelion, Almirall, AstraZeneca, Boehringer Ingelheim, Cephalon, Chiesi, GlaxoSmithKline, Hoffman La Roche, Merck, Novartis, Sanofi-Aventis, and Takeda; personal fees from Elevation Pharma, Napp Pharma, Forest, Pfizer, Navigant Consulting, IMS Consulting Group, ALK-Abello, and ICON; and a grant for his institution from Aeras.

SK has received grants for studies from Almirall, AstraZeneca, Boehringer Ingelheim, Chiesi, GlaxoSmithKline, Hoffman La Roche, Novartis, and Takeda; SK has received honoraria for lecturing or attending advisory boards from Almirall AstraZeneca, Boehringer Ingelheim, Chiesi, GlaxoSmithKline, and Novartis. CS is an employee of Almirall S.A., Barcelona, Spain.

EM and EGG are employees of AstraZeneca PLC, Barcelona, Spain.

CC is a former employee of Forest Research Institute, Forest Laboratories LLC, a subsidiary of Actavis, Jersey City, NJ, USA.

AL is a former employee of Almirall S.A., Barcelona, Spain.

\section{Authors' contributions}

DS was the co-ordinating investigator of the study, read and commented on the full study report, had full access to all the data, contributed to the writing of each draft of the manuscript and had final responsibility for the decision to submit for publication. PJ read and commented on the full study report and contributed to the interpretation of the data and the writing of each draft of the manuscript. EB and SK were investigators and contributed to the interpretation of the data and the writing of each draft of the manuscript. CS was the Clinical Trial Manager, EM was the statistician, AL was the Global Clinical Leader for the study and EGG was Global Project Leader. CS, EM, CC,
EGG and AL contributed to the design, conduct, analysis and interpretation of the study and contributed to the writing of each draft of the manuscript. All authors had full access to the data and take full responsibility for the content of the manuscript, including the data and analysis. All authors read and approved the final manuscript.

\section{Acknowledgements}

This study was funded by Almirall S.A., Barcelona, Spain, and Forest Laboratories LLC, a subsidiary of Actavis, New York, NY, USA. The sponsors were responsible for conception and design of the study and collection and analysis of data. The sponsors placed no restrictions on statements made in the final version of the manuscript or on the decision to submit the manuscript for publication and all authors had full access to the data. The authors thank all of the study investigators at each of the participating centres. The authors were assisted in the preparation of this manuscript by Suzanne McAllister, PhD, a professional medical writer with Complete Medical Communications (Macclesfield, UK). Medical writing support was funded by Almirall S.A., Barcelona, Spain.

\section{Funding}

Almirall S.A., Barcelona, Spain, and Forest Laboratories LLC, a subsidiary of Actavis, New York, NY, USA.

\section{Author details}

${ }^{1}$ University of Manchester, Medicines Evaluation Unit, Langley Building, University Hospital of South Manchester NHS Foundation Trust, Southmoor Road, Manchester M23 9QZ, UK. ${ }^{2}$ Infection and Immunity Institute, St George's, University of London, London, UK. ${ }^{3}$ Division of Pulmonology, Department of Medicine, University of Cape Town, Cape

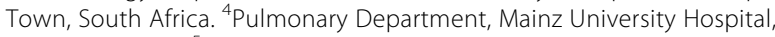
Mainz, Germany. ${ }^{5}$ Almirall R\&D Centre, Almirall, Barcelona, Spain.

${ }^{6}$ AstraZeneca PLC, Barcelona, Spain. ${ }^{7}$ Formerly of Forest Research Institute, Forest Laboratories LLC, a subsidiary of Actavis, Jersey City, NJ, USA.

${ }^{8}$ Formerly of Almirall S.A., Barcelona, Spain.

Received: 13 June 2014 Accepted: 3 November 2014 Published: 18 November 2014

\section{References}

1. Global Initiative for Chronic Obstructive Lung Disease: Global Strategy for the Diagnosis, Management and Prevention of Chronic Obstructive Pulmonary Disease. 2014. http://www.goldcopd.org/uploads/users/files/GOLD_Report_ 2013 Feb20.pdf.

2. Cazzola M, Calzetta L, Matera MG: beta(2) -adrenoceptor agonists: current and future direction. $\mathrm{Br} J$ Pharmacol 2011, 163:4-17.

3. Cazzola M, Page CP, Calzetta L, Matera MG: Pharmacology and therapeutics of bronchodilators. Pharmacol Rev 2012, 64:450-504.

4. IMS Health LS: IMS Data 5/2011-4/2012. Danbury, CT, US: IMS Health Incorporated; 2012

5. Tashkin DP, Ferguson GT: Combination bronchodilator therapy in the management of chronic obstructive pulmonary disease. Respir Res 2013, $14: 49$

6. Rudolf M, Tashkin DP: Bronchodilators - future role in the management of chronic obstructive pulmonary disease. Eur Respir Dis 2012, 8:108-115.

7. Cazzola M, Rogliani P, Matera MG: Aclidinium bromide/formoterol fumarate fixed-dose combination for the treatment of chronic obstructive pulmonary disease. Expert Opin Pharmacother 2013, 14:775-781.

8. Partridge MR, Karlsson N, Small IR: Patient insight into the impact of chronic obstructive pulmonary disease in the morning: an internet survey. Curr Med Res Opin 2009, 25:2043-2048.

9. Global Initiative for Chronic Obstructive Lung Disease: Global Strategy for the Diagnosis, Management, and Prevention of Chronic Obstructive Pulmonary Disease. 2010. http://www.goldcopd.org/Guidelines/guideline-2010-goldreport.html.

10. Leidy NK, Wilcox TK, Jones PW, Murray L, Winnette R, Howard K, Petrillo J, Powers J, Sethi S: Development of the EXAcerbations of Chronic obstructive pulmonary disease Tool (EXACT): a patient-reported outcome (PRO) measure. Value Health 2010, 13:965-975.

11. Leidy NK, Wilcox TK, Jones PW, Roberts L, Powers JH, Sethi S: Standardizing measurement of chronic obstructive pulmonary disease exacerbations: 
reliability and validity of a patient-reported diary. Am J Respir Crit Care Med 2011, 183:323-329.

12. Leidy NK, Murray LT: Patient-reported outcome (PRO) measures for clinical trials of COPD: the EXACT and E-RS. COPD 2013, 10:393-398.

13. Leidy NK, Murray LT, Jones $P$, Sethi S: Performance of the EXAcerbations of Chronic pulmonary disease Tool patient-reported outcome measure in three clinical trials of chronic obstructive pulmonary disease. Ann Am Thorac Soc 2014, 11:316-325.

14. European Medicines Agency: Guideline on Clinical Development of Fixed Combination Medicinal Products (CHMP/EWP/240/95) Rev.1. http://www.ema. europa.eu/docs/en_GB/document_library/Scientific_guideline/2009/09/ WC500003686.pdf

15. US Food and Drug Administration: Code of Federal Regulations. Title 21. Section 300.50. Fixed-Combination Prescription Drugs for Humans. http://www. accessdata.fda.gov/scripts/cdrh/cfdocs/cfCFR/CFRSearch.cfm?fr=300.50.

16. Benhamou D, Cuvelier A, Muir JF, Leclerc V, Le Gros V, Kottakis J, Bourdeix I: Rapid onset of bronchodilation in COPD: a placebo-controlled study comparing formoterol (Foradil Aerolizer) with salbutamol (Ventodisk). Respir Med 2001, 95:817-821.

17. Tashkin DP, Fabbri LM: Long-acting beta-agonists in the management of chronic obstructive pulmonary disease: current and future agents. Respir Res 2010, 11:149.

18. Kerwin EM, D'Urzo AD, Gelb AF, Lakkis H, Garcia Gil E, Caracta CF, ACCORD I study investigators: Efficacy and safety of a 12-week treatment with twice-daily aclidinium bromide in COPD patients (ACCORD COPD I). COPD 2012, 9:90-101.

19. Jones PW, Singh D, Bateman ED, Agusti A, Lamarca R, de Miquel G, Segarra R, Caracta C, Garcia Gil E: Efficacy and safety of twice-daily aclidinium bromide in COPD patients: the ATTAIN study. Eur Respir $J$ 2012, 40:830-836.

20. Aalbers R, Maleki-Yazdi MR, Hamilton A, Waitere-Wijker S, Pivovarova A, Schmidt O, Bjermer L: Dose-Finding Study for Tiotropium and Olodaterol When Administered in Combination via the Respimat Inhaler in Patients with COPD. Vienna, Austria: Poster presented at the European Respiratory Society Annual Congress; 2012

21. Bateman ED, Ferguson GT, Barnes N, Gallagher N, Green Y, Henley M, Banerji D: Dual bronchodilation with QVA149 versus single bronchodilator therapy: the SHINE study. Eur Respir J 2013, 42:1484-1494.

22. Donohue JF, Maleki-Yazdi MR, Kilbride S, Mehta R, Kalberg C, Church A Efficacy and safety of once-daily umeclidinium/vilanterol $62.5 / 25 \mathrm{mcg}$ in COPD. Respir Med 2013, 107:1538-1546.

23. Maltais F, Beck E, Webster D, Maleki-Yazdi MR, Seibt J-V, Arnoux A, Hamilton A: Four weeks once daily treatment with tiotropium+olodaterol $(\mathrm{BI} 1744)$ fixed dose combination compared with tiotropium in COPD patients [abstract]. Eur Respir J 2010, 36:1014s.

24. Reisner C, Fogarty C, Spangenthal S, Dunn L, Kerwin EM, Quinn D, Seale JP, Thomas M, St Rose E, Orevillo C: Novel combination of glycopyrrolate and formoterol MDI (GFF-MDI) provides superior bronchodilation compared to its components administered alone, tiotropium DPI, and formoterol DPI in a randomized, double-blind, placebo-controlled Phase $2 \mathrm{~b}$ study in patients with COPD [abstract]. Am J Resp Crit Care Med 2011, 183:A6435.

25. Jones PW, Beeh KM, Chapman KR, Decramer M, Mahler DA, Wedzicha JA: Minimal clinically important differences in pharmacological trials. Am J Respir Crit Care Med 2014, 189:250-255.

26. Donohue JF: Minimal clinically important differences in COPD lung function. COPD 2005, 2:111-124.

27. Kaptchuk TJ, Friedlander E, Kelley JM, Sanchez MN, Kokkotou E, Singer JP Kowalczykowski M, Miller FG, Kirsch I, Lembo AJ: Placebos without deception: a randomized controlled trial in irritable bowel syndrome. PloS One 2010, 5:e15591.

28. Westwood M, Bourbeau J, Jones PW, Cerulli A, Capkun-Niggli G, Worthy G: Relationship between $\mathrm{FEV}_{1}$ change and patient-reported outcomes in randomised trials of inhaled bronchodilators for stable COPD: a systematic review. Respir Res 2011, 12:40.

29. Rabe KF, Fabbri LM, Vogelmeier C, Kogler H, Schmidt H, Beeh KM, Glaab T: Seasonal distribution of COPD exacerbations in the prevention of exacerbations with tiotropium in COPD trial. Chest 2013 143:711-719.

30. Kessler R, Partridge MR, Miravitlles M, Cazzola M, Vogelmeier C, Leynaud D, Ostinelli J: Symptom variability in patients with severe COPD: a pan-European cross-sectional study. Eur Respir J 2011, 37:264-272.
31. Kew KM, Mavergames C, Walters JA: Long-acting beta2-agonists for chronic obstructive pulmonary disease. Cochrane Database Syst Rev 2013 10, CD010177.

32. Jansat JM, Lamarca R, Garcia Gil E, Ferrer P: Safety and pharmacokinetics of single doses of aclidinium bromide, a novel long-acting, inhaled antimuscarinic, in healthy subjects. Int J Clin Pharmacol Ther 2009, 47:460-468

33. Sentellas S, Ramos I, Albertí J, Salvà M, Antón F, Miralpeix M, Beleta J, Gavaldà A: Aclidinium bromide, a new, long-acting, inhaled muscarinic antagonist: in vitro plasma inactivation and pharmacological activity of its main metabolites. Eur J Pharm Sci 2010, 39:283-290.

doi:10.1186/1471-2466-14-178

Cite this article as: Singh et al.: Efficacy and safety of aclidinium bromide/formoterol fumarate fixed-dose combinations compared with individual components and placebo in patients with COPD (ACLIFORM-COPD): a multicentre, randomised study. BMC Pulmonary Medicine 2014 14:178

\section{Submit your next manuscript to BioMed Central and take full advantage of:}

- Convenient online submission

- Thorough peer review

- No space constraints or color figure charges

- Immediate publication on acceptance

- Inclusion in PubMed, CAS, Scopus and Google Scholar

- Research which is freely available for redistribution

Submit your manuscript at www.biomedcentral.com/submit
C Biomed Central 